This item was submitted to Loughborough's Research Repository by the author.

Items in Figshare are protected by copyright, with all rights reserved, unless otherwise indicated.

\title{
The effect of small-sided game formats on physical and technical performance in wheelchair basketball
}

PLEASE CITE THE PUBLISHED VERSION

https://doi.org/10.1123/ijspp.2017-0500

\section{PUBLISHER}

(C) Human Kinetics

\section{VERSION}

AM (Accepted Manuscript)

\section{PUBLISHER STATEMENT}

This work is made available according to the conditions of the Creative Commons Attribution-NonCommercialNoDerivatives 4.0 International (CC BY-NC-ND 4.0) licence. Full details of this licence are available at: https://creativecommons.org/licenses/by-nc-nd/4.0/

\section{LICENCE}

CC BY-NC-ND 4.0

\section{REPOSITORY RECORD}

Mason, Barry, Rienk van der Slikke, Michael Hutchinson, Monique Berger, and Vicky Goosey-Tolfrey. 2019. "The Effect of Small-sided Game Formats on Physical and Technical Performance in Wheelchair Basketball". figshare. https://hdl.handle.net/2134/27711. 
The effect of small-sided game formats on physical and technical performance in wheelchair basketball

\begin{tabular}{|r|l|}
\hline Journal: & International Journal of Sports Physiology and Performance \\
\hline Manuscript ID & IJSPP.2017-0500.R2 \\
\hline Manuscript Type: & Original Investigation \\
\hline Keywords: & $\begin{array}{l}\text { Activity profiles, Physiological demand, Video analysis, Wheelchair athletes, } \\
\text { Disability sport }\end{array}$ \\
\hline \multicolumn{2}{|c}{} \\
\hline
\end{tabular}




\section{Abstract}

2 Purpose: To examine effects of different small-sided games (SSG) on physical and technical 3 aspects of performance in wheelchair basketball (WB) players. Design: Observational cohort 4 study. Methods: Fifteen highly trained WB players participated in a single 5v5 (24-sec shot5 clock) match and three 3v3 SSGs (18-sec shot-clock) on a: i) full (FC); ii) half (HC) and; iii) 6 modified length court (MOD). During all formats, player's activity profiles were monitored 7 using an indoor tracking system and inertial measurement units. Physiological responses were 8 monitored via heart rate and rating of perceived exertion. Technical performance i.e. ball 9 handling was monitored using video analysis. Repeated measures ANOVA and effect sizes 10 (ES) were calculated to determine the statistical significance and magnitude of any 11 differences between game formats. Results: Players covered less distance and reached lower 12 peak speeds during $\mathrm{HC}(P \leq 0.0005$; ES $\geq$ very large $)$ compared to all other formats. Greater 13 distances were covered and more time was spent performing moderate and high speed 14 activity ( $P \leq 0.008$; ES $\geq$ moderate) during FC compared to all other formats. Game format 15 had little bearing on physiological responses and the only differences in technical 16 performance observed were in relation to $5 \mathrm{v} 5$. Players spent more time in possession, took 17 more shots and performed more rebounds in all 3v3 formats compared to $5 \mathrm{v} 5(P \leq 0.028$; ES $18 \geq$ moderate). Conclusions: Court dimensions affect the activity profiles of WB players 19 during 3v3 SSG, yet had little bearing on technical performance when time pressures (shot20 clocks) were constant. These findings have important implications for coaches to understand 21 which SSG format may be most suitable for physically and technically preparing WB players.

22 Keywords: Activity profiles, physiological demand, video analysis, wheelchair athletes, 23 disability sport 


\section{Introduction}

Wheelchair basketball (WB) is a 5v5 team sport characterised as an intermittent, aerobic-based activity interspersed with frequent bouts of high-intensity work that requires high levels of physical conditioning and technical skill. ${ }^{1,2}$ A substantial amount of research has explored the activity profiles, ${ }^{1,3,4}$ physiological $^{2,5,6}$ and technical demands ${ }^{7-9}$ of $5 \mathrm{v} 5 \mathrm{WB}$, yet little has focused on training strategies that may best prepare athletes for the demands of WB. ${ }^{6,10,11}$ Small-sided games (SSG) have emerged as one of the most common training strategies employed by coaches from team sports, since they have the ability to develop physical, technical and tactical competencies under competition-specific conditions and can also be used when athlete availability is limited. ${ }^{12}$ A limited number of studies have explored the effects of SSG in WB. ${ }^{6,10,11}$ However these studies have only considered the physiological effects of SSG with limited reference to $5 \mathrm{v} 5$ WB. Subsequently, the impact of SSG upon the activity profiles and technical demands of WB players have yet to be explored. The aforementioned studies have all focused on $4 \mathrm{v} 4$ game formats, whereas $3 \mathrm{v} 3$ is the more common SSG format within WB, which has its own set of rules and regulations, ${ }^{13}$ with a variety of formats played worldwide on different court dimensions. These include a: i) full court (FC) [28 x $15 \mathrm{~m}]$; ii) half court (HC) [14 x $15 \mathrm{~m}]$; iii) modified court (MOD) [22 x 15 $\mathrm{m}]$.

Substantial research has explored the physical and technical responses to different court dimensions during able-bodied (AB) $3 \mathrm{v} 3$ basketball. ${ }^{14-16}$ Increased activity profiles and physiological responses were observed during $3 \mathrm{v} 3$ on a full court, ${ }^{16}$ whereas the frequency of technical actions performed increased on a half court. ${ }^{14,15}$ However, the effects of different SSG formats on physical and technical aspects of performance specific to WB remain unknown. Subsequently the aims of the current study were to compare the activity profiles, physiological and technical demands during three formats of $3 \mathrm{v} 3 \mathrm{WB}(\mathrm{FC}, \mathrm{HC}, \mathrm{MOD})$ in 
50 relation to $5 \mathrm{v} 5 \mathrm{WB}$. It was hypothesised that the physical and technical demands would be 51 inversely related during $3 \mathrm{v} 3 \mathrm{WB}$, with an elevated physical demand during FC and improved 52 technical performance during HC. The findings from this study will provide coaches with a 53 better understanding of the effects of different SSG in WB and may be used to optimise 54 physical and technical training strategies.

\section{Methods}

Fifteen U22 international male wheelchair basketball players (age: $19 \pm 2$ years;

58 playing experience: $7 \pm 3$ years; classification range: $1.0-4.5$ ) participated in the current 59 study. Ethical approval for the procedures was acquired from the University's local ethical 60 advisory committee and written informed consent was obtained from all players prior to 61 participation. All players participated in four different WB game formats over two days. On 62 day one players competed in a standard 5v5 match, composed of $4 \times 10$-minute periods with 63 a 24-second shot-clock, a 14-point classification limit and substitutions permitted. ${ }^{13}$ Mean 64 playing time for all players during 5v5 was 20:23 \pm 06:53 minutes (range: 11:04 - 30:25 65 minutes). The following day players participated in three different formats of $3 v 3$ on a: i) full 66 court (FC); ii) half court (HC); iii) 22m length court (MOD). All participants were equally 67 inexperienced with all 3v3 formats. Coaches selected 5 balanced teams of 3 players with an 68 8.5-point classification limit. All teams played $2 \times 10$-minute periods (to most closely 69 replicate the mean playing time of 5v5) of each format against different teams using a 70 running game-clock and an 18-second shot-clock. No substitutions or timeouts were 71 permitted during the $3 \mathrm{v} 3$ game formats, which were scored and officiated. A minimum of 1072 minutes rest was ensured between each game to prevent fatigue from influencing 73 performance. Teams and opponents were identical across all 3v3 game formats. 
74 During all formats, players' activity profiles were monitored using a radio frequency75 based indoor tracking system sampling at $\sim 8 \mathrm{~Hz}$ (Ubisense, Cambridge, UK), which has 76 previously been validated for use within wheelchair court sports. ${ }^{17,18}$ Data collection 77 commenced at the beginning of each period and terminated at the end of each period and was 78 only paused during the 5v5 format during any extended stoppages (e.g. timeouts, equipment 79 calls). Since a running clock was used and no timeouts were permitted during the $3 \mathrm{v} 3$ formats, 80 data collection was only paused in the event of an equipment call. The activity accumulated 81 during all periods of each format was analysed to determine the relative distance covered $82\left(\mathrm{~m} \cdot \mathrm{min}^{-1}\right)$, peak speed $\left(\mathrm{m} \cdot \mathrm{s}^{-1}\right)$ and the relative time spent in 3 arbitrary speed zones: i) low 83 speed activity (LSA) $<1.5 \mathrm{~m} \cdot \mathrm{s}^{-1}$; ii) moderate speed activity (MSA) $1.5-3.0 \mathrm{~m} \cdot \mathrm{s}^{-1}$; iii) high 84 speed activity (HSA) $>3.0 \mathrm{~m} \cdot \mathrm{s}^{-1}$. Inertial measurement units (IMU) (Shimmer3, Shimmer 85 Sensing, Ireland) sampling at $199.8 \mathrm{~Hz}$ were attached to the frame of five randomly selected 86 players spanning the range of classifications (1.0, 2.0, 3.0, $3.5 \& 4.5)$ to determine the 87 magnitude of frame rotations and accelerations during each game format. All IMU data was 88 filtered using a $2^{\text {nd }}$ order low-pass Butterworth filter with a cut-off frequency of $25 \mathrm{~Hz}$. These 89 $\underline{\text { sensors have been previously used with wheelchair sports over extended periods and have }}$ been shown not drift over these periods. ${ }^{4}$ The number of rotations $\left(n \cdot \mathrm{min}^{-1}\right)$ performed were 91 categorised as: i) minor $<15^{\circ}$; moderate $15-165^{\circ}$; severe $>165^{\circ}$. Accelerations were 92 quantified as the relative movement time spent in 3 arbitrary zones: i) low acceleration 93 activity (LAA) $<1.0 \mathrm{~m} \cdot \mathrm{s}^{2}$; ii) moderate acceleration activity (MAA) $1.0-2.5 \mathrm{~m} \cdot \mathrm{s}^{2}$; iii) high 94 acceleration activity $(\mathrm{HAA})>2.5 \mathrm{~m} \cdot \mathrm{s}^{2}$. Heart rate was monitored wirelessly at 1-second intervals (Polar Team Pro System,

96 Polar, Kempele, Finland) during all formats. Peak $\left(\mathrm{HR}_{\text {peak }}\right)$ and mean heart rate $\left(\mathrm{HR}_{\text {mean }}\right)$ were 97 reported for all players and was paused during any breaks in play to align with the tracking 98 data. Immediately after each game format players provided an overall rating of perceived 
99 exertion (RPE) using the CR-10 scale. ${ }^{19}$ Players were familiar with the CR-10 scale and its 100 anchors, as it formed a regular part of their training.

All game formats were recorded using 2 synchronised video cameras (Sony HDR-

102 CX405, Tokyo, Japan) equipped with a wide angle conversion lens (Raynox HD-5050PRO,

103 Tokyo, Japan) and positioned along both baselines. Each camera focused on one half of the

104 court, with a slight overlap to ensure that activities were visible anywhere on court. Video 105 footage was analysed using Dartfish TeamPro Data 6.0 (Fribourg, Switzerland) by two 106 analysts experienced with the software and WB. A number of sport-specific activities were 107 coded for all individuals including possession (time in possession), balls received (number of 108 times a player receives a ball), balls caught (balls caught relative to balls received), passes 109 (number of passes made), long passes (long passes defined as a pass that bisects one or more 110 opponents, made relative to total passes), pass success rate (\% of successful passes), shots 111 (number of shots made), three-pointers (number of shots made behind the three-point line), 112 shot success rate (\% of successful shots), rebounds (number of defensive and offensive 113 rebounds made), forced turnovers (number of times a player forced a mistake from an 114 opponent) and turnovers (number of times a player turned possession over through an error).

115 To account for differences in playing time between $5 \mathrm{v} 5$ and $3 \mathrm{v} 3$ formats, resulting from 116 differences in timing (game-clock vs running clock) and rules relating to substitutions and 117 timeouts, technical activities were only analysed when the ball was in play across all formats.

118 Subsequently frequency-based technical actions were expressed as the number of times an 119 activity was performed relative to a fixed time (10-minutes). Each analyst re-coded the 120 activities of two randomly selected 10-minute periods for two players so that intra- and inter121 rater reliability could be determined. Intraclass correlation coefficients $\geq 0.96$ and $\geq 0.87$

122 were observed for intra- and inter-observer reliability respectively across all variables, which 123 were deemed acceptable based on a similar analyses with WB. ${ }^{9}$ 
124 All data were presented as means \pm standard deviation (SD). Repeated measures 125 analysis of variance (ANOVA) with a bonferroni correction was performed on all parameters, 126 except data from the inertial measurement units due to a limited sample size $(\mathrm{n}=5)$.

127 Statistical significance was accepted when $P<0.05$. Cohen's effect sizes (ES) $\pm 90 \%$ CI was 128 calculated to determine the magnitude of any differences in dependent variables between 129 game formats ${ }^{20}$ and were categorised as trivial $(<0.2)$, small $(0.2-0.6)$, moderate $(0.6-1.2)$, 130 large $(1.2-2.0)$ and very large $(>2.0){ }^{21}$

\section{Results}

Players covered significantly greater distance during FC $(P \leq 0.0005 ; \mathrm{ES} \geq$ large $)$ and

134 reached greater peak speeds during $5 \mathrm{v} 5(P \leq 0.020$; ES $\geq$ moderate $)$ compared to all other 135 formats (Table $1 \&$ 2). Distance covered and peak speeds were significantly lower during HC $136(P \leq 0.0005 ; \mathrm{ES} \geq$ very large $)$ compared to all other formats. More time was spent performing 137 MSA and HSA $(P \leq 0.008 ;$ ES $\geq$ moderate $)$ and less time performing $\operatorname{LSA}(P \leq 0.0005 ; \mathrm{ES} \geq$ 138 large) during FC compared to all other formats. Alternatively, more time was spent 139 performing LSA and less time performing MSA and HSA during HC compared to all formats $140(P \leq 0.0005 ; \mathrm{ES} \geq$ very large $)$. More time was spent performing MAA during FC and MOD 141 compared to $5 \mathrm{v} 5$ and more severe rotations were performed during $\mathrm{HC}$ compared to $5 \mathrm{v} 5$ and $142 \quad \mathrm{FC}(\mathrm{ES} \geq$ large).

143 Despite the changes in activity profiles, game format had little bearing on 144 physiological responses (Table $1 \& 2$ ). $\mathrm{HR}_{\text {peak }}$ was significantly higher during $5 \mathrm{v} 5$ compared 145 to $\mathrm{HC}(P=0.025$; ES - moderate $)$, whereas $\mathrm{HR}_{\text {mean }}$ was significantly elevated during $\mathrm{FC}$ in 146 relation to $\mathrm{HC}(P=0.001$; ES - moderate). Players also reported a higher RPE during 5v5 147 and FC compared to $\mathrm{HC}$ and $\mathrm{MOD}(P \leq 0.048$; ES - moderate). 
No significant or meaningful differences in technical performance were revealed 149 between any of the $3 \mathrm{v} 3$ game formats. The only differences in technical performance 150 observed were in relation to 5v5 (Table 3). Players spent more time in possession, took more 151 shots and performed more rebounds in all 3v3 formats compared to $5 \mathrm{v} 5(P \leq 0.028$ ES $\geq$ 152 moderate). Players received the ball more often and made more passes during FC and MOD 153 and forced more turnovers during HC compared to 5v5 ( $P \leq 0.045$; ES $\geq$ moderate).

\section{Discussion}

The current study was the first to explore both the physical and technical demands of

159

160

162

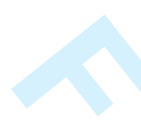

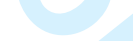


171 observed during SSG in AB sports ${ }^{16,22,23}$ and more relatedly, wheelchair rugby. ${ }^{24}$ Despite the

172 increased external demands imposed upon players during FC, internal demands did not 173 necessarily follow the same trend with mixed physiological responses revealed. No 174 meaningful differences in either $\mathrm{HR}_{\text {peak }}$ or $\mathrm{HR}_{\text {mean }}$ were revealed between $\mathrm{FC}$ and other 175 formats, although subjectively players perceived FC to be more demanding than both HC and 176 MOD, yet similar to 5v5. In addition, the increased activity profiles did not seem to have a 177 negatively effect-on players' technical performance during 3v3 FC as had been observed 178 during $\mathrm{AB}$ basketball. ${ }^{14,15}$ Subsequently, in line with the rules adopted by the current study 179 (no substitutions/timeouts, 18-second shot-clock) 3v3 FC could be a favourable SSG for 180 coaches to implement to physically overload players, without impairing technical 181 performance.

In contrast to $\mathrm{FC}$, the reduced court ratio per player associated with $\mathrm{HC}\left(35 \mathrm{~m}^{2}\right)$ led to a reduction in activity profiles, with less distance covered, lower peak speeds reached and more time spent performing LSA and less time performing MSA and HSA compared to all other formats. This corresponds with what has previously been observed during $\mathrm{AB}$ 186 basketball, whereby a reduction in external load was revealed during $3 \mathrm{v} 3$ matches on a half 187 court compared to both $3 \mathrm{v} 3$ and $5 \mathrm{v} 5$ on a full court. ${ }^{16}$ Alternatively players did perform more 188 severe rotations during $\mathrm{HC}$ compared to $5 \mathrm{v} 5$ and FC, which was a strategy likely employed to 189 create space on the smaller court. Although the execution of these-severe rotations is likely 190 associated with an increased metabolic power, this was not sufficient enough to offset the 191 other activity profiles that were diminished during HC, as physiologically this format was 192 also appeared-less demanding. Despite the reduced external and internal demands of HC, 193 minimal benefits in technical performance were revealed. Improvements in the frequency of 194 certain technical activities were only observed in relation to $5 \mathrm{v} 5$ and not versus other $3 \mathrm{v} 3$ 195 formats, which has been observed in $\mathrm{AB}$ basketball. ${ }^{15}$ The only additional value to HC from a 
196 technical perspective was that players forced moderately more turnovers compared to both 197 5v5 and FC. Therefore, although HC may not be an advisable SSG format for coaches 198 wishing to improve WB players physical and ball handling capabilities using the rules and 199 regulations adopted by the current study, this format may still be beneficial for developing 200 players defensive competencies. This in turn could lead to the development of players 201 effensive competencies, as increased pressure could be imposed on opponents, which could 202 prove to be an effective way to train their offensive skills.

During MOD activity profiles were all lower in relation to $\mathrm{FC}$, yet higher in relation 204 to HC, which could again be associated to the changes in court ratio per player, with MOD $205\left(55 \mathrm{~m}^{2}\right)$ eliciting more court space per player than $\mathrm{HC}$ and less than FC. Unlike other $3 \mathrm{v} 3$ 206 formats, MOD appeared to offer the closest representation of the activity profiles observed 207 during 5v5 WB. In particular, the distances covered and the time spent performing MSA were 208 similar between MOD $\left(85.1 \pm 4.5 \mathrm{~m} \cdot \mathrm{min}^{-1} ; 36.7 \pm 4.2 \%\right)$ and $5 \mathrm{v} 5\left(87.4 \mathrm{~m} \cdot \mathrm{min}^{-1} ; 38.4 \pm 4.1 \%\right)$ 209 respectively, with only small effects reported (Table 2). Similarly, physiological responses 210 were reflective of $5 \mathrm{v} 5 \mathrm{WB}$, with no meaningful differences in HR measures observed and 211 although players RPE was moderately lower for MOD, 90\% CI spanned zero. As with other $2123 \mathrm{v} 3$ formats, MOD only demonstrated meaningful increases in the frequency of technical 213 activities in relation to $5 \mathrm{v} 5$ as opposed to other SSGs. Subsequently, MOD may be an 214 advisable SSG format to implement when coaches are trying to maintain player's physical 215 conditioning without overloading them or during training phases when skill development is 216 valued above physical conditioning. Despite these advantages, MOD may be limited from a 217 logistical perspective, since court dimensions, lines and baskets need repositioning from their 218 standard positions. 
221 attributed to the different court ratios per player across each format. However, since technical 222 measures of performance only varied between 5v5 and SSGs, it would suggest that additional 223 parameters other than court ratio per player may affect technical performance during SSGs.

224 Other than a reduction in player numbers, the key difference between $5 \mathrm{v} 5$ and SSG formats 225 was a reduction in shot-clock from 24- to 18-seconds. Shot-clocks were controlledkept 226 eonsistent across all SSGs during the current study to minimise the number of confounding 227 factors that could influence the results. However, shot-clock duration could be a key 228 parameter for future SSG research in WB to consider in order to further affect players 229 physical and technical performance. Rhodes et al. ${ }^{24}$ revealed substantial increases in the 230 activity profiles of wheelchair rugby players when shot-clock duration was reduced during 231 3v3 SSGs. Although this study failed to account for any effects on technical performance, it 232 is envisage that a reduction in shot-clock duration may place further emphasis on technical 233 skill development, especially within the confined court space of HC. Future investigations 234 may also benefit from a slightly 1 Larger sample sizes would also be preferable in future so 235 that distinctions could be made between athletes of different classification and to ensure that 236 the effects of SSG formats on performance are similar for all classes. The current study 237 accounted for this to an extent by reducing the maximum classification limit from $14-(5 \mathrm{v} 5)$ 238 to 8.5 -points $(3 \mathrm{v} 3)$ to prevent the more impaired (lower classification) players from being 239 excluded. A larger sample size would have also been favourable for the IMU data, where it 240 was only possible to monitor five players. Subsequently few meaningful effects were 241 observed for the rotation and acceleration data between game formats. However, the methods 242 adopted for collecting and analysing this data was novel and may lay the foundations for 243 future studies to develop when quantifying mobility performance in wheelchair sports. 244 Minimal changes in physiological demand were also observed between game formats despite 245 clear changes in activity profiles, which may be a limitation of the HR-based methods used. 
246 Previous studies have reported similar findings during SSG, ${ }^{23,25}$ which could be attributed to 247 the large individual variability in HR observed for players. It could also be due to the 248 intermittent nature of WB, where frequent high-intensity efforts are performed, which could 249 lead to an underestimation of $\mathrm{HR}^{25}$ Subsequently, future investigations may benefit from the 250 use of blood lactate measurements to assess the physiological demands of SSG, as Kennet et 251 al. ${ }^{24}$ revealed less individual variability within this measure during intermittent team sports.

\section{Practical Applications}

254 - Coaches would benefit from implementing 3v3 SSG on a full court, when the principal 255 objective of training is to physically overload WB players, whilst maintaining sports256 specificity.

257 - 3v3 SSG on a modified length court could be implemented by coaching staff to maintain 258 physical fitness levels specific to the demands of competition, since this format shared 259 the most physical similarities to $5 \mathrm{v} 5 \mathrm{WB}$.

260 - The only additional benefit of $3 \mathrm{v} 3$ on half a court was that players performed more 261 severe rotations and forced more turnovers in relation to other SSGs. Therefore, in its 262 current format HC could be recommended to improve wheelchair handling skills and 263 defensive aspects of WB performance.

264 - Modifying court dimensions and subsequently the court ratio per player seemed to have a 265 clear effect on activity profiles during WB. However, only a reduction in player number 266 from $5 \mathrm{v} 5$ to $3 \mathrm{v} 3$ impacted upon players technical skills. In order to manipulate technical 267 performance within $3 \mathrm{v} 3 \mathrm{SSG}$, further modifications to shot-clock durations are advised. 


\section{Conclusions}

270 Modifying the court dimensions of 3v3 SSGs directly influences the activity profiles 271 and physiological responses of highly trained WB players, which can be elevated during FC 272 and reduced during $\mathrm{HC}$, mainly as a result of the different court ratios per player. 273 Alternatively, court dimensions had less of an impact upon technical performance during 274 SSGs, as the majority of meaningful differences existed between all $3 \mathrm{v} 3$ formats and $5 \mathrm{v} 5$. 275 Subsequently, a reduction in player number and differences in shot-clock restrictions likely 276 contribute to differences in technical performance. These findings have important 277 implications for WB coaches with regards to which SSG format may be best implemented at 278 various stages of the season.

279

\section{Acknowledgements} The authors would like to thank British Wheelchair Basketball and their players for 282 supporting this study. We would also like to extend our thanks to Welmoed Sinnema and 283 Daan Crombach for their assistance with the video analysis and to Loughborough University 284 for facilitating the study. 
286

287

288

289

290

291

292

293

294

295

296

297

298

299

300

301

302

303

304

305

306

307

308

309

310

311

312

313

314

315

316

317

318

319

320

321

322

323

324

1. Coutts KD. Dynamics of wheelchair basketball. Med Sci Sports Exerc. 1992; 24(2): 231234.

2. Bloxham LA, Bell GJ, Bhambhani Y, Steadward RD. Time motion analysis and physiological profile of Canadian world cup wheelchair basketball players. Sports Med Training Rehab. 2001; 10(3): 183-198.

3. Sporner ML, Grindle GG, Kelleher A, Teodorski EE, Copper R, Cooper RA. Quantification of activity during wheelchair basketball and rugby at the National Veterans Wheelchair Games: a pilot study. Prosthet Orthot Int. 2009; 33(3): 210-217.

4. van der Slikke RMA, Berger MAM, Bregman DJJ, Veeger HEJ. From big data to rich data: the key features of athlete wheelchair mobility performance. $J$ Biomech. 2016; 49: 3340-3346.

5. Croft LC, Dybrus S, Lenton J, Goosey-Tolfrey VL. A comparison of the physiological demands of wheelchair basketball and wheelchair tennis. Int J Sports Physiol Perform. 2010; 5: 301-315.

6. Iturricastillo A, Yanci J, Granados C, Goosey-Tolfrey VL. Quantifying wheelchair basketball match load: a comparison of heart rate and perceived exertion methods. Int $J$ Sports Physiol Perform. 2016; 11: 508-514.

7. Molik B, Laskin JJ, Kosmol A, Skucas K, Bida U. Relationship between functional classification levels and anaerobic performance of wheelchair basketball athletes. Res $Q$ Exerc Sport. 2010; 81(1): 69-73.

8. Gomez MA, Perez J, Molik B, Szyman RJ, Sampaio J. Performance analysis of elite men's and women's wheelchair basketball teams. J Sports Sci. 2014; 32(11): 1066-1075.

9. de Witte AMH, Hoozemans MJM, Berger MAM, van der Woude LHV, Veeger HEJ. Do field position and playing standard influence athlete performance in wheelchair basketball? J Sports Sci. 2016; 34(9): 811-820.

10. Yanci J, Iturricastillo A, Granados C. Heart rate and body temperature response of wheelchair basketball players in small-sided games. Int J Perform Anal Sport. 2014; 14: 535-544.

11. Iturricastillo A, Yanci J, Arcos AL, Granados C. Physiological responses between players with and without spinal cord injury in wheelchair basketball small-sided games. Spinal Cord. 2016; 54(12): 1152-1157.

12. Halouani J, Chtorou H, Gabbett T, Chaouachi A, Chamari K. Small-sided games in team sports training: a brief review. $J$ Strength Cond Res. 2014; 28(12): 3594-3618.

13. International Wheelchair Basketball Federation. Official wheelchair basketball rules 2014. Available at: http://www.wheelchairbasketball.ca/wpcontent/uploads/2015/03/2014_IWBF_Rules_V2.pdf Accessed 13 December 2016.

14. McCormick BT, Hannon JC, Newton M, Schultz B, Miller N, Young W. Comparison of physical activity in small-sided basketball games versus full-sided games. Int $J$ Sports Sci Coach. 2012; 7(4): 689-697. 
15. Atli H, Koklu Y, Alemdaroglu U, Kocak FU. A comparison of heart rate response and frequencies of technical actions between half-court and full-court 3-a-side games in high school female basketball players. J Strength Cond Res. 2013; 27(2): 352-356.

16. Schelling X, Torres L. Accelerometer load profiles for basketball-specific drills in elite players. J Sports Sci Med. 2016; 15: 585-591.

17. Rhodes JM, Mason BS, Perrat B, Smith M, Goosey-Tolfrey VL. The validity and reliability of a novel indoor player tracking system for use within wheelchair court sports. J Sports Sci. 2014; 32(17): 1639-1647.

18. Rhodes JM, Mason BS, Perrat B, Smith MJ, Malone LA, Goosey-Tolfrey VL. Activity profiles of elite wheelchair rugby players during competition. Int J Sports Physiol Perform. 2015; 10: 318-325.

19. Borg G. Borg's Perceived Exertion and Pain Scales, Champaign, IL, Human Kinetics, 1998.

20. Cohen J. Statistical Power Analysis for the Behavioral Sciences, $2^{\text {nd }}$ ed., Hillsdale, NJ, Lawrence Earlbaum Associates, 1988

21. Batterham AM, Hopkins WG. Making meaningful inferences about magnitudes. Int $J$ Sports Physiol Perform. 2006; 1: 50-57.

22. Casamichana D, Castellano J. Time-motion, heart rate, perceptual and motor behaviour demands in small-sided soccer games: effects of pitch size. J Sports Sci. 2010; 28(14): 1615-1623.

23. Kennet DC, Kempton T, Coutts AJ. Factors affecting exercise intensity in rugby-specific small-sided games. $J$ Strength Cond Res. 2012; 26(8): 2037-2042.

24. Rhodes JM, Mason BS, Paulson TAW, Goosey-Tolfrey VL. Game-simulation drill design alters the speed profiles of wheelchair rugby players. Int J Sports Physiol Perform. 2017; doi: 10.1123/ijspp.2016-0700 (Epub ahead of print).

25. Paulson TAW, Mason B, Rhodes J, Goosey-Tolfrey VL. Individualized internal and external training load relationships in elite wheelchair rugby players. Front Physiol. 2015; 6(388): $1-7$. 
Table 1 Mean (SD) performance measures during each of the game formats

\begin{tabular}{|c|c|c|c|c|}
\hline & \multirow[t]{2}{*}{$5 v 5$} & \multicolumn{3}{|c|}{$3 v 3$} \\
\hline & & FC & HC & MOD \\
\hline \multicolumn{5}{|l|}{ Activity profiles } \\
\hline Relative distance $\left(\mathrm{m} \cdot \mathrm{min}^{-1}\right)$ & $87.4(4.1)$ & $97.5(6.1)$ & $68.6(5.7)$ & $85.1(4.5)$ \\
\hline Peak speed $\left(\mathrm{m} \cdot \mathrm{s}^{-1}\right)$ & $4.69(0.31)$ & $4.36(0.31)$ & $3.33(0.30)$ & $4.13(0.35)$ \\
\hline LSA (\% time) & $56.4(3.8)$ & $49.7(5.4)$ & $73.8(5.8)$ & $59.7(4.1)$ \\
\hline MSA ( $\%$ time) & $38.4(4.1)$ & $42.5(5.1)$ & $25.7(5.8)$ & $36.7(4.2)$ \\
\hline HSA (\% time) & $5.1(1.4)$ & $7.6(2.7)$ & $0.3(0.3)$ & $3.4(1.5)$ \\
\hline LAA ( $\%$ time) & $62.7(3.4)$ & $55.0(4.7)$ & $59.5(4.5)$ & $56.5(5.0)$ \\
\hline MAA (\% time) & $23.0(0.8)$ & $26.2(2.1)$ & $25.0(1.7)$ & $25.5(1.8)$ \\
\hline HAA ( $\%$ time) & $14.2(3.4)$ & $18.8(3.0)$ & $15.4(3.1)$ & $18.0(3.3)$ \\
\hline Minor rotations $\left(\mathrm{n} \cdot \mathrm{min}^{-1}\right)$ & $31.5(6.6)$ & $31.3(6.0)$ & $24.9(3.6)$ & $28.4(4.3)$ \\
\hline Moderate rotations $\left(\mathrm{n} \cdot \mathrm{min}^{-1}\right)$ & $25.6(2.2)$ & $27.3(3.5)$ & $25.6(4.1)$ & $27.2(5.0)$ \\
\hline Severe rotations $\left(\mathrm{n} \cdot \mathrm{min}^{-1}\right)$ & $5.4(1.0)$ & $5.2(0.5)$ & $6.9(0.5)$ & $6.0(0.8)$ \\
\hline \multicolumn{5}{|l|}{ Physiology } \\
\hline $\mathrm{HR}_{\text {peak }}$ (beats. $\mathrm{min}^{-1}$ ) & $183(11)$ & $178(15)$ & $173(10)$ & $181(13)$ \\
\hline $\mathrm{HR}_{\text {mean }}\left(\right.$ beats $\cdot \mathrm{min}^{-1}$ ) & $152(11)$ & $155(14)$ & $146(12)$ & $152(15)$ \\
\hline $\mathrm{RPE}(\mathrm{AU})$ & $5.4(1.1)$ & $5.5(1.2)$ & $4.4(1.1)$ & $4.4(1.4)$ \\
\hline \multicolumn{5}{|l|}{ Technical } \\
\hline Possession (s) & $46.3(30.2)$ & $76.9(38.8)$ & $81.0(42.1)$ & $69.9(32.5)$ \\
\hline Balls received (n/10-min) & $10.1(4.7)$ & $13.4(4.5)$ & $12.2(4.4)$ & $14.0(4.5)$ \\
\hline Balls caught $(\%)$ & $97.9(5.9)$ & $97.4(4.7)$ & $96.4(3.9)$ & $97.6(3.2)$ \\
\hline Passes (n/10-min) & $9.9(4.4)$ & $14.4(4.6)$ & $12.0(3.6)$ & $14.1(4.4)$ \\
\hline Long passes $(\%)$ & $37.1(21.8)$ & $39.0(15.7)$ & $47.6(18.8)$ & $41.4(16.9)$ \\
\hline Pass success rate $(\%)$ & $96.8(4.8)$ & $95.2(4.6)$ & $93.6(6.7)$ & $96.4(5.8)$ \\
\hline Shots (n/10-min) & $3.7(2.4)$ & $6.2(2.8)$ & $6.8(3.5)$ & $7.2(3.3)$ \\
\hline Three pointers (n/10-min) & $0.2(0.4)$ & $0.6(0.9)$ & $0.3(0.7)$ & $0.3(0.7)$ \\
\hline Shot success rate $(\%)$ & $52.8(24.7)$ & $40.7(19.6)$ & $37.3(20.0)$ & $42.3(17.6)$ \\
\hline Rebounds (n/10-min) & $1.6(1.2)$ & $2.7(1.7)$ & $3.5(1.9)$ & $3.4(2.1)$ \\
\hline Forced turnovers (n/10-min) & $0.3(0.4)$ & $0.4(0.4)$ & $1.0(1.1)$ & $0.8(0.9)$ \\
\hline Turnovers (n/10-min) & $0.2(0.5)$ & $0.2(0.3)$ & $0.4(0.4)$ & $0.4(0.7)$ \\
\hline
\end{tabular}


Table 2 Differences in physical performance between game formats [ES $( \pm 90 \% \mathrm{CI})$ ].

\begin{tabular}{|c|c|c|c|c|c|c|c|}
\hline & ANOVA & 5 v 5 vs. FC & 5 v 5 vs. HC & 5 v 5 vs. MOD & FC vs. HC & FC vs. MOD & HC vs. MOD \\
\hline \multicolumn{8}{|l|}{ Activity profiles } \\
\hline Relative distance & $<0.0005$ & $\begin{array}{c}2.0^{* *} \\
(0.9,3.0)\end{array}$ & $\begin{array}{c}3.8^{* *} \\
(2.4,5.2)\end{array}$ & $\begin{array}{c}0.5 \\
(-0.3,1.4)\end{array}$ & $\begin{array}{c}4.9^{* *} \\
(3.2,6.6)\end{array}$ & $\begin{array}{c}2.3^{* *} \\
(1.2,3.4)\end{array}$ & $\begin{array}{c}3.2^{* *} \\
(1.9,4.5)\end{array}$ \\
\hline Peak speed & $<0.0005$ & $\begin{array}{c}1.1^{*} \\
(0.2,2.0)\end{array}$ & $\begin{array}{c}4.5^{* *} \\
(2.9,6.0)\end{array}$ & $\begin{array}{c}1.7^{*} \\
(0.7,2.7)\end{array}$ & $\begin{array}{c}3.4^{* *} \\
(2.1,4.7)\end{array}$ & $\begin{array}{c}0.7 \\
(-0.2,1.6)\end{array}$ & $\begin{array}{c}2.5^{* *} \\
(1.3,3.6)\end{array}$ \\
\hline LSA & $<0.0005$ & $\begin{array}{c}1.4^{* *} \\
(0.5,2.4)\end{array}$ & $\begin{array}{c}3.6^{* *} \\
(2.2,4.9)\end{array}$ & $\begin{array}{c}0.8^{*} \\
(-0.1,1.7)\end{array}$ & $\begin{array}{c}4.3^{* *} \\
(2.8,5.9)\end{array}$ & $\begin{array}{c}2.0^{* * *} \\
(1.0,3.1)\end{array}$ & $\begin{array}{c}2.8^{* *} \\
(1.6,4.0)\end{array}$ \\
\hline MSA & $<0.0005$ & $\begin{array}{c}0.9^{* *} \\
(0,1.8)\end{array}$ & $\begin{array}{c}2.5^{* *} \\
(1.4,3.7)\end{array}$ & $\begin{array}{c}0.4 \\
(-0.5,1.3)\end{array}$ & $\begin{array}{c}3.1^{* *} \\
(1.8,4.3)\end{array}$ & $\begin{array}{c}1.2^{* *} \\
(0.3,2.2)\end{array}$ & $\begin{array}{c}2.2^{* *} \\
(1.1,3.2)\end{array}$ \\
\hline HSA & $<0.0005$ & $\begin{array}{c}1.2^{* *} \\
(0.2,2.1)\end{array}$ & $\begin{array}{c}4.7^{* *} \\
(3.1,6.4)\end{array}$ & $\begin{array}{c}1.2^{*} \\
(0.3,2.1)\end{array}$ & $\begin{array}{c}3.8^{* *} \\
(2.4,5.2)\end{array}$ & $\begin{array}{c}1.9^{* *} \\
(0.9,3.0)\end{array}$ & $\begin{array}{c}2.9^{* *} \\
(1.7,4.1)\end{array}$ \\
\hline LAA & - & $\begin{array}{c}1.9 \\
(0.1,3.6)\end{array}$ & $\begin{array}{c}0.8 \\
(-0.7,2.3)\end{array}$ & $\begin{array}{c}1.5 \\
(-0.2,3.1)\end{array}$ & $\begin{array}{c}1.1 \\
(-0.5,2.7)\end{array}$ & $\begin{array}{c}0.3 \\
(-1.2,1.8)\end{array}$ & $\begin{array}{c}0.6 \\
(-0.9,2.1)\end{array}$ \\
\hline MAA & - & $\begin{array}{c}2.0 \\
(0.2,3.8)\end{array}$ & $\begin{array}{c}1.5 \\
(-0.2,3.2)\end{array}$ & $\begin{array}{c}1.8 \\
(0.1,3.5)\end{array}$ & $\begin{array}{c}0.6 \\
(-0.9,2.1)\end{array}$ & $\begin{array}{c}0.4 \\
(-1.1,1.8)\end{array}$ & $\begin{array}{c}0.3 \\
(-1.2,1.8)\end{array}$ \\
\hline HAA & - & $\begin{array}{c}1.4 \\
(-0.2,3.1)\end{array}$ & $\begin{array}{c}0.4 \\
(-1.1,1.9)\end{array}$ & $\begin{array}{c}1.1 \\
(-0.5,2.7)\end{array}$ & $\begin{array}{c}1.1 \\
(-0.5,2.7)\end{array}$ & $\begin{array}{c}0.3 \\
(-1.2,1.7)\end{array}$ & $\begin{array}{c}0.8 \\
(-0.7,2.3)\end{array}$ \\
\hline Minor rotations & - & $\begin{array}{c}0.0 \\
(-1.4,1.5)\end{array}$ & $\begin{array}{c}1.2 \\
(-0.4,2.9)\end{array}$ & $\begin{array}{c}0.6 \\
(-0.9,2.1)\end{array}$ & $\begin{array}{c}1.3 \\
(-0.3,2.9)\end{array}$ & $\begin{array}{c}0.6 \\
(-0.9,2.9)\end{array}$ & $\begin{array}{c}0.9 \\
(-0.7,2.4)\end{array}$ \\
\hline Moderate rotations & - & $\begin{array}{c}0.6 \\
(-0.9,2.1)\end{array}$ & $\begin{array}{c}0 \\
(-1.4,1.5)\end{array}$ & $\begin{array}{c}0.4 \\
(-1.1,1.9)\end{array}$ & $\begin{array}{c}0.5 \\
(-1.0,1.9)\end{array}$ & $\begin{array}{c}0 \\
(-1.4,1.5)\end{array}$ & $\begin{array}{c}0.4 \\
(-1.1,1.8)\end{array}$ \\
\hline Severe rotations & - & $\begin{array}{c}0.3 \\
(-1.2,1.7)\end{array}$ & $\begin{array}{c}1.9 \\
(0.1,3.7)\end{array}$ & $\begin{array}{c}0.7 \\
(-0.8,2.2)\end{array}$ & $\begin{array}{c}3.4 \\
(1.1,5.7)\end{array}$ & $\begin{array}{c}1.2 \\
(-0.4,2.8)\end{array}$ & $\begin{array}{c}1.3 \\
(-0.3,3.0)\end{array}$ \\
\hline Physiology & & & & & & & \\
\hline $\mathrm{HR}_{\text {peak }}$ & 0.016 & $\begin{array}{c}0.4 \\
(-0.5,1.2)\end{array}$ & $\begin{array}{c}1.0^{*} \\
(0.1,1.9)\end{array}$ & $\begin{array}{c}0.2 \\
(-0.7,1.0)\end{array}$ & $\begin{array}{c}0.4 \\
(-0.5,1.3)\end{array}$ & $\begin{array}{c}0.2 \\
(-0.6,1.1)\end{array}$ & $\begin{array}{c}0.7 \\
(-0.2,1.6)\end{array}$ \\
\hline $\mathrm{HR}_{\text {mean }}$ & 0.033 & $\begin{array}{c}0.2 \\
(-0.6,1.1)\end{array}$ & $\begin{array}{c}0.5 \\
(-0.3,1.4)\end{array}$ & $\begin{array}{c}0 \\
(-0.9,0.9)\end{array}$ & $\begin{array}{c}0.7^{* *} \\
(-0.2,1.6)\end{array}$ & $\begin{array}{c}0.2 \\
(-0.7,1.1)\end{array}$ & $\begin{array}{c}0.4 \\
(-0.4,1.3)\end{array}$ \\
\hline RPE & $<0.0005$ & $\begin{array}{c}0.1 \\
(-0.8,0.9)\end{array}$ & $\begin{array}{c}0.9^{*} \\
(0,1.8)\end{array}$ & $\begin{array}{c}0.8^{*} \\
(-0.1,1.7)\end{array}$ & $\begin{array}{c}1.0^{*} \\
(0,1.9)\end{array}$ & $\begin{array}{l}0.8^{* *} \\
(0,1.7)\end{array}$ & $\begin{array}{c}0 \\
(-0.9,0.9)\end{array}$ \\
\hline
\end{tabular}


Table 3 Differences in technical performance between game formats [ES $( \pm 90 \% \mathrm{CI})]$.

\begin{tabular}{|c|c|c|c|c|c|c|c|}
\hline & ANOVA & 5 v 5 vs. FC & 5 v 5 vs. $\mathrm{HC}$ & 5 v 5 vs. MOD & FC vs. HC & FC vs. MOD & HC vs. MOD \\
\hline Possessions & $<0.0005$ & $\begin{array}{c}0.9^{* *} \\
(0,1.8)\end{array}$ & $\begin{array}{c}1.0^{* *} \\
(0.1,1.8)\end{array}$ & $\begin{array}{c}0.8^{*} \\
(-0.1,1.6)\end{array}$ & $\begin{array}{c}0.1 \\
(-0.8,1.0)\end{array}$ & $\begin{array}{c}0.2 \\
(-0.7,1.1)\end{array}$ & $\begin{array}{c}0.3 \\
(-0.6,1.2)\end{array}$ \\
\hline Balls received & 0.008 & $\begin{array}{c}0.7^{*} \\
(-0.2,1.6)\end{array}$ & $\begin{array}{c}0.5 \\
(-0.4,1.3)\end{array}$ & $\begin{array}{c}0.9^{*} \\
(0,1.7)\end{array}$ & $\begin{array}{c}0.3 \\
(-0.6,1.1)\end{array}$ & $\begin{array}{c}0.1 \\
(-0.7,1.0)\end{array}$ & $\begin{array}{c}0.4 \\
(-0.5,1.3)\end{array}$ \\
\hline Balls caught & 0.830 & $\begin{array}{c}0.1 \\
(-0.8,0.9)\end{array}$ & $\begin{array}{c}0.3 \\
(-0.6,1.2)\end{array}$ & $\begin{array}{c}0.1 \\
(-0.8,0.9)\end{array}$ & $\begin{array}{c}0.2 \\
(-0.6,1.1)\end{array}$ & $\begin{array}{c}0.1 \\
(-0.8,0.9)\end{array}$ & $\begin{array}{c}0.3 \\
(-0.5,1.2)\end{array}$ \\
\hline Passes & $<0.0005$ & $\begin{array}{c}1.0^{*} \\
(0.1,1.9)\end{array}$ & $\begin{array}{c}0.5 \\
(-0.3,1.4)\end{array}$ & $\begin{array}{c}1.0^{*} \\
(0.1,1.9)\end{array}$ & $\begin{array}{c}0.6 \\
(-0.3,1.5)\end{array}$ & $\begin{array}{c}0.1 \\
(-0.8,0.9)\end{array}$ & $\begin{array}{c}0.6 \\
(-0.3,1.5)\end{array}$ \\
\hline Long passes & 0.067 & $\begin{array}{c}0.1 \\
(-0.8,1.0)\end{array}$ & $\begin{array}{c}0.5 \\
(-0.4,1.4)\end{array}$ & $\begin{array}{c}0.2 \\
(-0.6,1.1)\end{array}$ & $\begin{array}{c}0.5 \\
(-0.4,1.4)\end{array}$ & $\begin{array}{c}0.2 \\
(-0.7,1.0)\end{array}$ & $\begin{array}{c}0.4 \\
(-0.5,1.2)\end{array}$ \\
\hline Pass success rate & 0.477 & $\begin{array}{c}0.3 \\
(-0.5,1.2)\end{array}$ & $\begin{array}{c}0.6 \\
(-0.3,1.4)\end{array}$ & $\begin{array}{c}0.1 \\
(-0.8,0.9)\end{array}$ & $\begin{array}{c}0.3 \\
(-0.6,1.1)\end{array}$ & $\begin{array}{c}0.2 \\
(-0.6,1.1)\end{array}$ & $\begin{array}{c}0.5 \\
(-0.4,1.3)\end{array}$ \\
\hline Shots & $<0.0005$ & $\begin{array}{c}1.0^{* *} \\
(0.1,1.9)\end{array}$ & $\begin{array}{c}1.0^{* *} \\
(0.1,1.9)\end{array}$ & $\begin{array}{c}1.2^{* *} \\
(0.3,2.1)\end{array}$ & $\begin{array}{c}0.2 \\
(-0.7,1.0)\end{array}$ & $\begin{array}{c}0.3 \\
(-0.5,1.2)\end{array}$ & $\begin{array}{c}0.1 \\
(-0.7,1.0)\end{array}$ \\
\hline Three pointers & 0.137 & $\begin{array}{c}0.6 \\
(-0.3,1.4)\end{array}$ & $\begin{array}{c}0.2 \\
(-0.7,1.0)\end{array}$ & $\begin{array}{c}0.2 \\
(-0.7,1.0)\end{array}$ & $\begin{array}{c}0.4 \\
(-0.5,1.2)\end{array}$ & $\begin{array}{c}0.4 \\
(-0.5,1.2)\end{array}$ & $\begin{array}{c}0 \\
(-0.9,0.9)\end{array}$ \\
\hline Shot success rate & 0.139 & $\begin{array}{c}0.5 \\
(-0.3,1.4)\end{array}$ & $\begin{array}{c}0.7 \\
(-0.2,1.6)\end{array}$ & $\begin{array}{c}0.5 \\
(-0.4,1.4)\end{array}$ & $\begin{array}{c}0.2 \\
(-0.7,1.0)\end{array}$ & $\begin{array}{c}0.1 \\
(-0.8,0.9)\end{array}$ & $\begin{array}{c}0.3 \\
(-0.6,1.1)\end{array}$ \\
\hline Rebounds & 0.002 & $\begin{array}{c}0.8^{*} \\
(-0.1,1.6)\end{array}$ & $\begin{array}{c}1.2^{* *} \\
(0.3,2.1)\end{array}$ & $\begin{array}{c}1.1^{*} \\
(0.2,2.0)\end{array}$ & $\begin{array}{c}0.4 \\
(-0.4,1.3)\end{array}$ & $\begin{array}{c}0.4 \\
(-0.5,1.2)\end{array}$ & $\begin{array}{c}0.1 \\
(-0.8,1.0)\end{array}$ \\
\hline Forced turnovers & 0.048 & $\begin{array}{c}0.3 \\
(-0.6,1.1)\end{array}$ & $\begin{array}{c}0.9^{*} \\
(0,1.7)\end{array}$ & $\begin{array}{c}0.7 \\
(-0.2,1.6)\end{array}$ & $\begin{array}{c}0.7 \\
(-0.2,1.6)\end{array}$ & $\begin{array}{c}0.6 \\
(-0.3,1.4)\end{array}$ & $\begin{array}{c}0.2 \\
(-0.7,1.1)\end{array}$ \\
\hline Turnovers & 0.781 & $\begin{array}{c}0 \\
(-0.9,0.9)\end{array}$ & $\begin{array}{c}0.4 \\
(-0.4,1.3)\end{array}$ & $\begin{array}{c}0.3 \\
(-0.5,1.2)\end{array}$ & $\begin{array}{c}0.6 \\
(-0.3,1.4)\end{array}$ & $\begin{array}{c}0.4 \\
(-0.5,1.2)\end{array}$ & $\begin{array}{c}0 \\
(-0.9,0.9)\end{array}$ \\
\hline
\end{tabular}

Key: denotes a statistically significant difference at ${ }^{*} P<0.05 ;{ }^{* *} P<0.01$. 